\title{
THE CORPORATE AGILITY'S BAROMETER OF THE CONSTRUCTION COMPANY
}

\author{
Jevgenijs LOCOVS ${ }^{1}$, Elīna GAILE-SARKANE ${ }^{2}$ \\ ${ }^{1,2}$ Riga Technical University, Riga, Latvia \\ Corresponding author e-mail: jevgenijs.locovs@gmail.com
}

\begin{abstract}
Corporate agility is not a futuristic dream. It is a contemporary tool each construction company should have in its toolbox for daily use. In this article the authors identified and discussed the factors allowing to determine the level of construction company's corporate flexibility. In their approach to determine all the major factors affecting construction company's level of corporate flexibility, the authors used available data from different pertinent sources for systematic literature overviews; they also held interviews with experts in the field. For this purpose, the authors created questionnaire sets to evaluate the level of corporate flexibility within a given construction company. The questionnaire had to determine the existing situation in the company, its functionality within different departments, its collegiality and interrelationships between co-workers, subordinates, and superiors, to explore the level of corporate flexibility, and much more. Based on the research results, it became possible to make a direct correlation between the level of the corporate flexibility of the given construction company and its performance. The already repeatedly mentioned corporate flexibility directly affected both corporate activities (supportive and primary) and internal and external environment. The research confirmed that corporate flexibility is the balance between the needed bureaucracy and organizational flexibility. In evaluating the results, the conclusion was made that in order to maximize the outcome of corporate efforts, focus should be made on several issues: measures to reduce bureaucracy, and most importantly, the scale of overly high level of responsiveness and flexibility, which may raise concerns about a chaotic and misbalanced structural organization within the company, when subsequent decisions should be made to improve the existing situation and prevent a potential danger.
\end{abstract}

Keywords: Corporate agility, Construction company, Performance improvement.

JEL Classification: L26, M14, M21, O31

\section{INTRODUCTION}

As determined by many researchers (Sull, 2010; Aghina et al., 2015; Appelbaum et al., 2017, etc.), corporate agility plays an important role in the successful performance of any modern company. The segmentation (Oberlender, 2000), low productivity (Ritz, 1994), high level of all kinds of regulatory issues (de Witt et al., 2005) and slow pace of modernization (Langf \& Male, 2001) bring construction industry to one of the first places among of industries lacking corporate agility. By measuring the corporate agility, it is possible to determine weaknesses in the company (Erande \& Verma, 2008). The authors decided to conduct the field research and create a set of questionnaires that would allow to define the level of corporate agility of any 
given construction company. Consequently, this research would assist the company to identify, based on its level of agility, the weak points in its functionality, and provide guidelines for improvement. A corporate agility of any construction company is shaped by quite a few parameters: Cultural aspects, organizational behaviour, corporate governance, strategy, human capital, etc. The improvement of corporate agility has a great positive affect on the performance of the company (Haneberg, 2011), on its responsiveness and flexibility, its ability to re-adjust responding to internal and external challenges, while using minimal resources.

The authors used the following theoretical and academic frameworks: the finding of Hofstede, corporate governance frameworks; organizational behavior frameworks, the Contingency theory, the Expectancy theory, Maslow's Theory of Human Motivation, the Bureaucracy theory, findings developed by Dr. Ichak Adizes, and also holding interviews with the representatives of construction industry.

The purpose of this article is to identify and give thoughts on the factors allowing to determine the corporate agility level of a construction company.

Methodology is based on literature overview and personal interviews conducted by the authors with different individuals representing construction industry.

There was a scientific goal set: To determine main factors that affect corporate agility of a construction company through interviews with industry's professionals.

The research structured using the so-called four blocks:

1. Identification of the factors allowing to determine the corporate agility level of a construction company;

2. The methodology for evaluation of the corporate agility level of a construction company;

3. Analysis and interpretation of the obtained data;

4. Implementation of the necessary changes.

The current article will review the first two blocks, while the last two will be left for the further research.

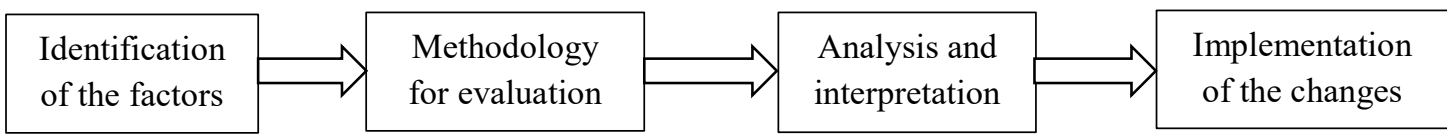

Fig. 1. The blocks of the research (created by authors).

In fact, a company may periodically use this questionnaire not only to determine, but also to monitor the changes.

\section{IDENTIFICATION OF THE FACTORS AFFECTING THE CORPORATE AGILITY OF THE CONSTRUCTION COMPANY}

Authors performed a systematic literature overview to determine main factors affecting corporate agility of a construction company. The results were confirmed by the interviews performed (face to face or via conference calls) with fifteen CEOs, CFOs, CLOs, Construction and HR Directors, Senior Project Managers from 4 countries and 11 construction companies. All the respondents were asked to list at least 
five factors affecting, in their view, the corporate agility of their company. 84 (eightyfour) factors were mentioned. The authors used the content analysis approach to determine main factor affecting corporate agility of a construction company. The responses obtained were organized in broader groups and resulted in 8 (eight) main factors. Each factor has its own level of significance in evaluating the way it affects corporate agility.

Table 1. Eight factors affecting corporate agility (created by authors).

\begin{tabular}{|l|l|c|}
\hline$\#$ & The main factors affecting corporate agility & Shares of responses in \%o \\
\hline 1 & Poor structure (hierarchy, bureaucracy, procedures, experience) & $25 \%$ \\
\hline 2 & Human Resources (broad thinking, motivation, skilled manpower) & $23 \%$ \\
\hline 3 & Poor management & $14 \%$ \\
\hline 4 & Poor planning (including use of technology and analytical tools) & $12 \%$ \\
\hline 5 & Communication (Internal/External. Reputation) & $9 \%$ \\
\hline 6 & Lack of strategy/vision & $8 \%$ \\
\hline 7 & Financial issues & $5 \%$ \\
\hline 8 & Influence of PESTEL factors & $4 \%$ \\
\hline & Total & $\mathbf{1 0 0 \%}$ \\
\hline
\end{tabular}

The authors reviewed these factors in detail with following conclusions:

- Poor structure (hierarchy, bureaucracy, procedures, experience). The interviewed managers have attributed the biggest share to this particular factor. They mentioned that the improper hierarchical structure, operational system, overall unnecessary bureaucracy, incompetent shareholders' intervention in the operational process, rigid ubiquitous approaches do not allow a company properly and flexibly react to the changes. Moreover, even if a potential threat or change/challenge is timely determined, the reaction time appears to be too long and necessary resources to be used are too costly.

- Human Resources (broad thinking, motivation, skilled manpower). This factor was considered the next, reaching share of $23 \%$, since the professional quality of all employees play the most important role in the company's success. All experts agreed that the main problem of construction industry is lack of broad thinking and presence of motivated professionals at all levels. This, in turn, leads to the delays and losses due to the poorly performed works. Another important issue related to human resources is a priority given by employees to their own personal goals over those of their team or company.

- Poor management. This factor is directly related to the quality of human capital. The lack of self-sample and proper leadership, pessimism among the top management, lack of ability by the top management to inspire the employees, poor and involvement in the daily operational decision-making leads to emotional distress, feeling of mess, of 'running through the thick forest' instead of 'driving on the paved road'. The gap between managerial strata enforces the inability of the company qualitatively operate and timely prevent threats and entertain the opportunities.

- Poor planning (including lack of use of technology and analytical tools). This factor is a non-stop persisting problem of the construction industry. The construction organizations often lose money because of allowing themselves to be involved in highly complex projects requiring significant resources because of lack of proper operational planning. Consequently, because of late orders, untimely or 
missing information flow, poor risk management, lack of assisting tools (for instance, suitable software), missing the "no return" point as a result, and at the end mistakes/defects must be eliminated applying huge effort and resource investment. Such short-term planning and 'pumping out water out of the ship' only allows to keep the ship afloat without any opportunity to navigate to the port of destination.

- Communication (internal/ external, reputation). Based on the results of the questionnaire, this factor was also named as quite important one with the share of $10 \%$. The truth is, all employees highly appreciate the reputation of the company they are working for, as well as the relationship between their company and external stakeholders. However, the observation shows a permanently present distressing moment: poor exchange of information between different departments, lack of necessary information and leadership input to make decisions, practically non-existent feedback between decision-makers and their employees, - all of which serve as demotivating factor.

- Lack of strategy/vision. This problem, understandably, origins at the top-level management. As it was observed, It the decision-makers often lacks even the understanding, why those in power should set a clear strategy and define goals. However, even when trying to implement the necessary strategic points and define the efforts needed to reach the set goals, top managers do not consider it important to share their points of view related to the future development of the company to the lower levels of the chain of command. Thus, the lack of understanding of the goals, the inability of thinking "out of the box", failure of the core top management to set tasks, to implement proper strategy impedes company's development, and, as a result, nobody knows where they are going, nobody knows what to expect and what to be ready for; hence, demotivation and confusion. One of the corner stones of the corporate agility and responsiveness is a clear understanding of corporate goals and tasks, of ways how to achieve these goals, while ways, considering all the circumstances, can be adjusted. Otherwise, prompt and effective operation based on consistent transformation is impossible.

- Financial issues. There is not a construction company (actually, any company at all) that can operate without strong financial background (credit and guarantee lines, warranties, working capital, etc.). However, it should be noted that within the given research, this issue was discussed more as an existing and necessary source allowing fast development and proper reaction to changes. It is always better to have more money than less, however, often companies that have "deep pockets", do not act proactively, being reluctant to demonstrate agility.

- Influence of PESTEL factors. It was observed, that in relation to company's proper development, the influence of Political, Economic, Social, Technological, Environmental and Legal macro-external factors minimal impact on company's agility and/or responsiveness. Construction industry is one of the most bureaucratized ones, thus all the described external factors are considered as more or less given, and a company is supposed to operate as agile and responsive as possible, within the given limits. The important issue to be established here is whether these factors change too often or too quickly, meaning that a dynamic change of this degree may negatively affect a company by blocking its ability to be timely prepared.

It is important to outline that almost half of the responses - $48 \%$ - are attributable to only two factors - human resources and structural organization within a company, the next $36 \%$ were considered as contributed by management, planning, and 
communication. The authors interpreted these factors within the framework of the concepts discussed above and concluded that these are human resources, corporate governance and organizational behaviour since the mentioned three components make $84 \%$ of responses related to their influence on the corporate agility. The significance of the factors under discussion was supported by both, theoretical and practical approach. The further research will focus on establishing a tool allowing to determine the level of corporate agility and to provide guidelines for its improvement.

\section{THE METHODOLOGY FOR THE EVALUATION OF CONSTRUCTION COMPANY'S LEVEL OF CORPORATE AGILITY}

To determine the level of corporate agility in a company, the authors developed questionnaires using the following theoretical and academic frameworks:

Table 2. Theoretical framework for a questionnaire

\begin{tabular}{|l|l|}
\hline \multicolumn{1}{|c|}{ The research aspects } & \multicolumn{1}{c|}{ Literature and studies/The authors } \\
\hline Cultural aspects & Hofstede 2011, Gelfand et al 2009, Friberg \& Eldring 2013 \\
\hline $\begin{array}{l}\text { Best practices of corporate } \\
\text { governance frameworks }\end{array}$ & $\begin{array}{l}\text { Yao 2009, Maassen 2002, Kast \&. Rosenweing 1979, L'huillier } \\
\text { 2014, Epstein 1999 }\end{array}$ \\
\hline $\begin{array}{l}\text { Best practices of organizational } \\
\text { behaviour framework }\end{array}$ & $\begin{array}{l}\text { Mintzberg et al. 2006, Kondalkar 2007, Wagner III \& } \\
\text { Hollenbeck 2010, Burnes 2017, Oberlander 2000, Ritz 1994, } \\
\text { Langford \& Male 2001, Rajasekhar 2017, Brockmann, \& } \\
\text { Girmscheid 2015, Cardosa et al 2015, Brooks\& Spillane 2016 }\end{array}$ \\
\hline Best Human Resource practices & $\begin{array}{l}\text { Mayo 1933, McGregor 1960, Dan-Asabe \& Radosavljevic, 2009, } \\
\text { Eaton 2008, Siew 2014, Burnes 2017, Cardosa et al 2015, Burnes } \\
\text { 2017, Oberlander 2000, Ritz 1994, Langford \& Male 2001, } \\
\text { Brockmann, \& Girmscheid 2015, Brooks\& Spillane 2016 }\end{array}$ \\
\hline The Contingency theory & Mintzberg, 1979 \\
\hline The Expectancy theory & Vroom 1964, Vroom \& Deci 1977 \\
\hline $\begin{array}{l}\text { Maslow's Theory of Human } \\
\text { Motivation }\end{array}$ & Maslow 1943 \\
\hline The Bureaucracy theory & Weber 1948, Friedrich 1952 \\
\hline $\begin{array}{l}\text { Corporate lifecycle findings } \\
\text { developed by Dr. Ichak Adizes }\end{array}$ & Adizes 1999 \\
\hline $\begin{array}{l}\text { Interviews with construction } \\
\text { industry's representatives }\end{array}$ & Construction industry's experts \\
\hline
\end{tabular}

This questionnaire should help to reveal the existing situation in a company, its functionality within different departments, its collegiality and inter-relationships between co-workers, subordinates and superiors, employees' attitude towards the organization, to explore the level of corporate agility of a company, and many more. Shortly speaking, it will include a variety of internal data, that most of the employees would not be willing to share, especially with the top managers of the company.

\section{RESULTS}

There might be different reasons why: possible fear to lose their job, personal issues, or peculiarities of their nature, or else; however, the crucial point of any assessment and analysis is the true and reliable data received during the initial phase of the interview, leading to conclusions and development of consequent improvement programs. This is the reason why the authors developed the seven-step program named 
"AGILITY" to perform assessment of a construction organization, with analytical approach towards obtained results, providing respective recommendations. It would be highly advisable to distribute the questionnaire as broadly as possible within an organization.

"A" (Agent) - Selection of an independent agent. It is highly recommended the interview to be performed by a hired external consultant, a construction industry professional, with no personal involvement/interest/relationship with the company under assessment. This person should be known to be honest and reputable, so that potential respondents would trust their personal data/information would not be disclosed. allowing the interviewees to openly respond, with no fear. If, for any reason a company would decide to proceed with this assessment using internal resources, there should be serious consideration in convincing interviewees to provide veridical data. One of the options might be assessment provided by cross-department management, when head of one department performs an interview with employees of another department; however, this approach still does not exclude conflict of interests and/or similar divergences.

"G" (Guidance) - The Agent becomes a Guide. He/she should explain to the interviewees the questionnaire, its purpose and the whole process. The introductory communication is one of the most important phases of the interview, which cannot be skipped. The proper introduction and friendly environment help to develop sense of participation and cooperation among the interviewees, but while, on the other hand, the Agent/Guide still controls the process. Interviewees should clearly understand why they are questioned, what they should expect as consequences, being sure that their superiors are sincerely interested in their answers; the management must communicate the necessity for interviews within the company, and the whole process should be as transparent as possible. The purpose of the procedure should be explained, the strategic goals should be revealed, a few known failures or weaknesses should be described, however, the spirit of willingness to grow and to improve must prevail. Clear rules and limits of the deploying questionnaire must be set and communicated. All participants should believe in good faith and confidentiality of this the process. All questions must be read and explained, together with assessment criteria. There should be also discussed the process after the questionnaire is filled. Agent/Guide should encourage questions and active participation/involvement. The whole process may take place either in person or via video conference, less recommended are written instructions. The latter may compliment the visual component. It is important to emphasize that the respondents may use the additional field in questionnaires for remarks in case they are not sure about something or would like to expand/comment their answer.

"I" (Implementation) - Implementing the questionnaire, there should be as many people involved as possible. The person should complete his/her answers by giving numbers and indicating his/her agreement and/or disagreement with the one provided the questionnaire should be completed by as many employees as possible from all professional levels and departments. The respondents should not be asked to complete the questionnaire by hand, to avoid people fearing identification. The best way to proceed would be to provide a platform where no personal identification is required, and request for identification is set as optional. The interview could be performed with several individuals at the same time or by groups, via smartphones or laptops, and within certain period of time. 
"L" (Learning) - Learn and analyze the results. Each answer has assigned a score. The total score is summarized after the whole table is full; the higher the number the lower is the level of company's agility, which may be determined, if necessary, completely, covering the whole organization under research, as well as its part. However, here is important to note that in analyzing the results, the focus should be given not only to the particular department, but also to a respondent per se, since the perception of any state of affairs, including description of corporate agility, varies depending on the professional position/professional level of the responding employee. List those who identified him/herself. Thus, it is important to assess the respondents by groups, allowing the researcher to see how different groups of respondents evaluate the corporate agility of their company and the working place/conditions. There are following issues to be considered: the working place/department, education, gender, years of experience, - all of which may help the researcher o come to proper conclusions from different angles of view. Another important issue is paying attention to the number of unanswered questions and additional remarks, which may also play an important role demonstrating what is missing within the company under research.

"I" (Interview) - It would be useful for research to have at least 10\%-20\% of participants to be interviewed personally, which is not always possible. Depending on the scale and structure of the company, the interviewer should define the number of people to be interviewed and their background. It is recommended to begin with those, who identified themselves, since the discussion with them will be more open and relaxed. It is not less important, while interviewing those who refused/avoided to identify themselves, to understand what the reason for such behavior was. It is always better to proceed with this interview in a cozy comfortable place, preferably not at the place of work helping the respondents to feel relaxed, for example, coffee place at work or outside the place of work or a joint walk with the interviewer. In any case, the interviewer, after analyzing the previously obtained written results, must figure out how to proceed with the mentioned personal interviews; there may be different approaches - it may be either a discussion in general, when important issues of interest are imperceptibly asked or the whole questionnaire may be openly discussed. In the latter case the data collected would be definitely more precise. In addition to the given questions, there should be also discussed ideas for improvement expressed by employees during the interview. It is recommended that all acting heads of departments, top management and, when possible, shareholders, are interviewed as well.

"T" (Truth) - This is the phase when the results are presented, and the true situation revealed. The result should include analysis of the situation in the whole company, as well as separately, in each department. Here should be presented the following results: The viewpoints of different groups interviewed, the discovered weak spots/insufficiencies/failures, after which recommended guidelines for improvement should be presented. If the client/company decides to deploy the suggested guidelines, the latter should turn into the clearly defined tasks, goals, and paths of actions. There may be a subsequent need of overall review of corporate structure and operation in a company per se, as well as in some particular departments.

"Y" -Year(s) - It must be noted here that the development and implementation of measures to deal with problems mentioned above is a highly time-consuming process, with no expectations for immediate results. Having a comprehensive picture in mind, it is recommended that a company under research repeat the questionnaire a year after all failures had been described and suggestions accepted and implemented; sometimes it may be worth even to rephrase the questions, to assure the actual answers and 
memorized ones. Such an approach in no way excludes any follow-up meetings and monitoring discussions, the latter will provide a feeling or indication, while the overall questionnaire would give a comprehensive picture. The results of these activities would show real-time changes/improvements.

The 7 (seven) steps AGILITY model showing implementation of a questionnaire specifically developed to assess the level of corporate agility of a construction company.

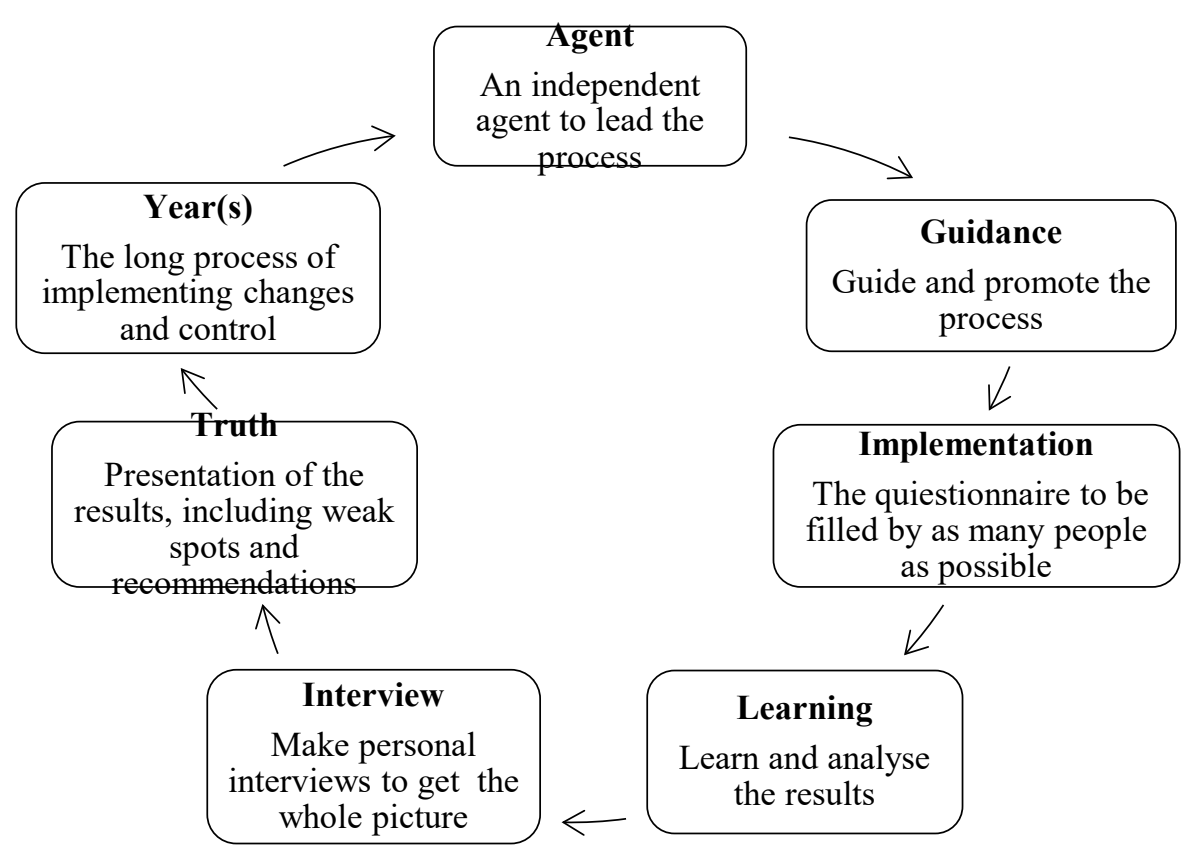

Fig. 2. The 7 (seven) steps AGILITY model (developed by the authors).

The authors developed the frameworks for the questionnaire based on both, theoretical and practical findings. In order to receive comprehensive and detailed analysis, the questionnaire should be divided into 9 blocks: Authors developed the frameworks for the questionnaire, which is based on both theoretical and practical findings. In order to receive comprehensive and detailed analysis, the questionnaire should be divided into 9 blocks: $1^{\text {st }}$ block "Human resources", $2^{\text {nd }}$ block questions "Communication including reputation", $3^{\text {rd }}$ block "Operational planning and approach", $4^{\text {th }}$ block "Management and Organizational behavior", $5^{\text {th }}$ block "Structure and Corporate governance", $6^{\text {th }}$ block "Strategy and Values", $7^{\text {th }}$ block "Financial data", $8^{\text {th }}$ block "The influence of PESTEL factors (political, economic, social, technological, environmental, legal - external macro factors)", 9 $9^{\text {th }}$ block “General valuation".

As was mentioned above the authors left the detailed elaboration of questionnaire for further research. Similarly, was done for two more steps needed to complete the evaluation of the corporate agility of the construction company: "Analysis and interpretation of the received data" and "Implementation of change". Authors suggest developing about 7-10 questions for each questionnaire block, addressing both personal and corporate aspects, which should be described by the employees.

The questionnaire per se is important, but it is only one of the tools the Agent should use is evaluating the company. Personal interviews, small group workshops, perhaps, a 
box for suggestions might also be an option to understand and explore the internal corporate climate of a company.

\section{CONCLUSION}

The research's findings proved that level of corporate agility has a direct impact on the corporate performance. It affects both the internal and external environments of the construction company. The corporate agility of all departments has a direct positive impact on both supportive and primary activities.

While evaluating the questionnaire's results, it is important to remember that agility is total lack of any limitation and ability to accept any change. On the other hand, the excessive bureaucracy is an agility killer. The research's results clearly show the direct correlation between the corporate agility and the development of a company, with ability to adjust itself to any changes and/or challenges. Consequently, the excessive bureaucracy, corporate rigidity testifies to the opposite. Thus, evaluating and analyzing the obtained results, a company on its way to progress should focus on issues to reduce bureaucracy, simultaneously taking measures to balance the development between deep rigidity leading to lack of operational responsiveness and overly agile structure leading to chaotic environment without proper leadership and management.

It is recommended that the last two blocks: "Analysis and interpretation of the received data" and "Implementation of the necessary changes" should be explored during the further research and following discussions. The required changes to improve corporate agility may call for a different approach within corporate culture, development of a long-term process of "reformation", changing the relationship between the management and employees, as well es inter-relationship between the teams, leading to changes in their way of thinking. It may also require the structural change that may occur relatively rapidly but will be followed up by slower process of "getting used to" or, in other words, institutionalization. The latter 1 may initiate some cultural and behavioral changes within the organization, which, most probably, will occur in a natural way.

The required/recommended changes should be evaluated from the implementation point of view. It is highly important to take all factors into consideration while the improvement plan is being developed. The top management should be sure to understand whether their company is stable enough to undergo transformation in its culture and structure, if needed, which way would be better for their business - the smaller steps involving some particular procedures or an overall "corporate revolution".

\section{REFERENCES}

Adizes, I. (1999). Managing Corporate Lifecycle. Engelwood Cliffs, NJ: Prentice Hall.Burnes B., (2017). Managing change. 7th ed., Pearson, UK.

Aghina W., De Smet, A., \& Weerde, K. (2015). Agility: It rhymes with stability. Mc Kinsey.

Appelbaum, S.H., Calla, R., Desautels, D., \& Hasan L. (2017). The challenges of organizational agility, part 1. Industrial and Commercial Training, 49(1), 6-14. https://doi.org/10.1108/ICT-05-2016-0027

Brockmann, C. \& Girmscheid, G. (2010). Inter- and Intra organizational Trust in International Construction Joint Ventures. ASCE Journal for Construction Engineering Management, 136, 353360. https://doi.org/10.1061/(ASCE)CO.1943-7862.0000142

Brooks, T. \& Spillane J. (5-7 September 2016). Does Inappropriate Quality Control Demotivate Workers? A Critical Review. In: P W Chan and C J Neilson (Eds.) Proceedings of the 32nd Annual ARCOM Conference, Manchester, UK. Association of Researchers in Construction Management, 2, 823-832. 
Cardosoa P., Domingueza C., \& Paivaab A. (2015). Hints to Improve Motivation in Construction Companies. Conference on Enterprise Information Systems, International Conference on Project Management, Conference on Health and Social Care Information Systems and Technologies, CENTERIS, ProjMAN, HCist. Procedia Computer Science, 64, 1200-1207. https://doi.org/10.1016/j.procs.2015.08.513

Dailey, R. (2016). Organizational behavior. Edinburgh Business School.

DeWitt, S., Yakowenko, G., Bohuslav, T., Ferguson, T., Hoelker E., Molenaar K., Schiess G., Smythe J., Triplett J., Wagman R. (2005). Construction Management Practices in Canada and Europe. Office of International Programs. US Department of Transportation. Federal Highway Administration.

Dan-Asabe, D. \& Radosavljevic, M. (7-9 September 2009). Do construction companies need to match employees' expectations? In: Dainty, A. (Ed) Procs 25th Annual ARCOM Conference, Nottingham, UK, Association of Researchers in Construction Management, 1223-32.

Langford, D., \& Male, S. (2001). Strategic Management in Construction. Blackwell Publishing company, UK.

Eaton, D. (2008). Human Resource Management in construction. Salford.

Erande, A., \& Verma, A. (2008). Measuring Agility of Organizations - A Comprehensive Agility Measurement Tool (CAMT). Old Dominion University, Proceedings of the 2008 IAJC-IJME International Conference.

Epstein, D., \& O'Halloran, S. (1999). Delegating Powers: A Transaction Cost Politics Approach to Policy Making Under Separate Powers. Cambridge University Press.UK.

Friberg, J.H. \& Eldring L. (2013). Labour migrants from Central and Eastern Europe in the Nordic countries. Patterns of migration, working conditions and recruitment practices. Nordic Council of Ministers.

Gelfand, M.J., Erez, M, and Aycan, Z. (2006). Cross-Cultural Organizational Behavior. The Annual Review of Psychology, 58, 479-514. https://doi.org/10.1146/annurev.psych.58.110405.085559

Haneberg, L. (2011). Training for agility, $T+D$, 65(9), 50-55.

Hofstede, G. (2011). Dimensionalizing Cultures: The Hofstede Model in Context. Online Readings in Psychology and Culture, 2(1). https://doi.org/10.9707/2307-0919.1014

Kondalkar V.G. (2007). Organizational behaviour. New Age International (P) Limited, Publishers, New Delhi, India.

Kast, F.E., \& Rosenweing, J.E. (1979). Organization and Management. McGraw-Hill New York, USA. L'huillier, B., (2014). What does 'corporate governance' actually mean? Corporate Governance Int. Journal of Business in Society, 14(3), 300-319. https://doi.org/10.1108/CG-10-2012-0073

Mintzberg, H., Ahlstrand, B., \& Lampel, J. (2006). Strategy Safari: A Guided Tour Through the Wilds of Strategic Management, The Free Press, New York, USA.

Mintzberg, H. (1979). The Structuring of organizations, Prentice-Hall, USA.

Maslow, A. H. (1943). A theory of human motivation. Psychological Review, 50, 390-396.

Mayo, E. (1933). The Human Problems of an Industrial Civilization. Routledge; 1st edition, USA.

Maassen, G.F. (2002). An International Comparison of Corporate Governance Models, 3rd edition, Spencer.

McGregor, D. M. (1960). The Human Side of Enterprise. McGraw Hill, New York.

Oberlender, G.D. (2000). Project management for engineering and construction. International Edition. The McGraw-Hill Companies, Inc. USA.

Ritz G.J. (1944). Total Construction Project Management. McGraw-Hill, Inc. USA.

Rajasekhar, R. (January 2017). Financial Performance Evaluation of Construction Industries. International Journal of Scientific and Research Publications, 7(1), 157-175. Retrieved from http://www.ijsrp.org/research-paper-0117/ijsrp-p6129.pdf

Sull, D. (2010). Competing through organizational agility. McKinsey quarterly.

Siew R. Y. J. (2014). Human resource management in the Construction Industry - Sustainability Competencies. Construction Economics and Building, 14(2), 87-103. https://doi.org/10.5130/AJCEB.v14i2.3957

Vroom, V. H. (1964). Work and Motivation, New York, NY: Wiley.

Vroom, V. H. \& Deci, E. L. (1977). Management and Motivation: Selected Readings, Penguin Education, Penguin Books Ltd., Harmondsworth, UK.

Weber, M. (1948). Max Weber: Essays in sociology. Routledge and Kegan Paul: London, UK.

Wagner III, J.A., Hollenbeck, J.R. (2010). Organizational Behavior: Securing Competitive Advantage., Routledge, New York, USA, p. 5.

Yao, Y. (2009). Historical Dynamics of the Development of the Corporate Governance, Journal of Politics and Law, 2(4), 167-174. https://doi.org/10.5539/jpl.v2n4p167 


\section{AUTHORS' SHORT BIOGRAPHY}

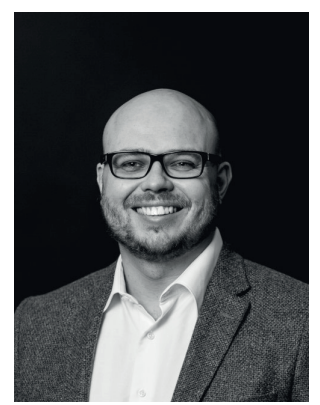

Jevgenijs Locovs is a general \& technical management executive, experienced leader with an extensive record of hands-on operations, tactical successes and strategic planning expertise in both real estate development and construction. Founder and CEO (till 2020) of international construction and manufacturing company with the turnover exceeding $100 \mathrm{M}$ eur. A passion for integration of sustainability programs that reduce costs, leverage company's core strengths and resources, develop top-performing, multi-disciplined functional teams operating in domestic and international markets, enhance competitiveness, increase revenues and ensure the best quality for the end consumer. Internationally trained multi-faceted professional with significant experience and comprehensive knowledge in: due-diligences, marketing and business planning, elaboration of design briefs and tenders documentation, formation and management of multi-disciplined international design and project management teams, contract drafting and negotiations, design and construction processes leading, management and supervision of more than $1000000 \mathrm{~m} 2$ of residential, office, retail, industrial, infrastructure and offshore construction projects. Proven ability of determination and implementation of the most practical, creative and innovative solutions within constraints of time and financing. Deep understanding of company's critical business requirements, identifying deficiencies and potential opportunities. Broad work experience with state and large international financial institutions. Jevgenijs holds degree of Executive Master of Business Administration from Stockholm School of Economics, and Bachelor's and Master's degree in civil engineering from Riga Technical University. Member of the Latvian Institution of Civil Engineers.

E-mail: jevgenijs.locovs@gmail.com

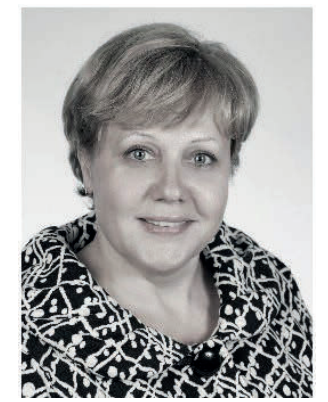

Prof. Dr. Elina Gaile - Sarkane is a dean of the Faculty of Engineering Economics and Management (FEEM), Riga Technical University (RTU), also she is teaching variety of courses in organization management and new product development. Dr. Gaile-Sarkane focuses her research on topics of management, innovation and technology transfer, entrepreneurship and various aspects of business

Elina Gaile-Sarkane have more than 150 scientific publications in management, economics and the related fields, and more than 35 of them published at internationally recognized journals or conference proceedings with indexing at international data basis (such as Thomson and Reuter, SCOPUS, EBSCO etc.). Dr. Gaile-Sarkane is an author and/or co-author of 4 text books, 3 monographs, 2 patents. She had been a supervisor of many $\mathrm{PhD}$ students and four doctors, contributed as the expert in promotional procedure of new doctors and as the consultant in doctoral thesis development in Latvia and abroad.

E-mail: elina.gaile-sarkane@rtu.lv

ORCID: http://orcid.org/0000-0002-7509-527 